\title{
Extraction Behavior of Hydrogen Ion by an Ionic Liquid Mixture of Aliquat 336 and Cyanex 272 in Chloride Solution
}

\author{
Minh Nhan Le ${ }^{1}$, Seong Ho Son ${ }^{2}$, and Man Seung Lee ${ }^{1, *}$ \\ ${ }^{I}$ Department of Advanced Materials Science \& Engineering, Institute of Rare Metal, \\ Mokpo National University, Chonnam 58554, Republic of Korea \\ ${ }^{2}$ Korea Institute of Industrial Technology, Incheon Technology Service Centre, Incheon 21999, Republic of Korea
}

\begin{abstract}
During the extraction of metal ions from a weak acidic chloride solution by ionic liquids consisting of an organophosphorus extractant and Aliquat 336, the equilibrium $\mathrm{pH}$ is sometimes observed to be higher than the initial $\mathrm{pH}$. To compare the hydrogen ion extraction behavior of tertiary and quaternary amines, Alamine 336, Aliquat 336 and their mixture with Cyanex 272, and an ionic liquid (prepared by mixing Cyanex 272 and Aliquat $336, \mathrm{R}_{4} \mathrm{NA}$ ) were employed in solvent extraction experiments at a $\mathrm{pH}$ range from 0.05 to 5 . $\mathrm{R}_{4} \mathrm{NA}$ showed the highest extraction percentage of hydrogen ions. The initial $\mathrm{pH}$ of the chloride solution had a great effect on the extraction of hydrogen ions and the equilibrium $\mathrm{pH}$ value produced by these extractants. The order of hydrogen ion extraction was $\mathrm{R}_{4} \mathrm{NA}>$ Alamine $336>$ mixture of Alamine 336 and Cyanex 272. The addition of sodium chloride improved phase separation. The solvent extraction reaction of hydrogen ions with $\mathrm{R}_{4} \mathrm{NA}$ in the chloride solution was verified by applying a slope analysis method to the extraction data. UV-Vis and FT-IR spectra indicated a strong interaction between the hydrogen ions and $\mathrm{R}_{4} \mathrm{NA}$ during the extraction. The obtained results provide some information on the change in solution $\mathrm{pH}$ during the extraction of metal ions from weak acidic solution by an ionic liquid $\left(\mathrm{R}_{4} \mathrm{NA}\right)$.
\end{abstract}

(Received December 31, 2018; Accepted January 18, 2019)

Keywords: solvent extraction, hydrogen ion, ionic liquids, aliquat 336, cyanex 272 .

\section{INTRODUCTION}

Inorganic acids such as hydrochloric, nitric, and sulfuric acid have been widely used in hydrometallurgical processes for the dissolution of desired valuable metals from ores or secondary resources. The nature of these inorganic acids affects the subsequent processes used to separate the metal ions from the leaching solution. And because the effluents from these separation steps contain these inorganic acids, their disposal is of environmental concern [1,2]. A number of methods are available to treat effluents containing inorganic acids, including neutralization, diffusion dialysis, membrane process, precipitation, solvent extraction, and ion exchange processes [3-5].

\footnotetext{
- Minh Nhan Le : 박사과정, 손성호: 연구원, 이만승: 교수

*Corresponding Author: Man Seung Lee

[Tel: +82-61-450-2492, E-mail: mslee@mokpo.ac.kr]

Copyright (c) The Korean Institute of Metals and Materials
}

Among these methods, solvent extraction is considered to be one of the most effective for extracting inorganic acids from effluents. During solvent extraction, the reaction between the extractants and the protons (hydrogen ions) of the acid might be responsible for the extraction of these acids. Tertiary amines such as Alamine 308 (tri-isooctyl amine), Alamine 336 (tri-C8-10 alkyl amines), TDA (tri-ndodecyl amine), TEHA (tris 2-ethylhexyl amine), TIOA (triisooctyl amine), and TOA (trioctylamine) are generally used for the selective extraction of hydrogen ions. Most of the extraction reactions follow the protonation mechanism [6-8]. In another approach, neutral extractants such as TBP (tributyl phosphate), MDP (methyl diphenyl phosphate), and Cyanex 923 (a mixture of four trialkylphosphine oxides) can also extract hydrogen ions efficiently via the solvating mechanism [9,10]. While ammonium salts like Aliquat 336 or cationic extractants like Cyanex 272 cannot by themselves extract inorganic acids, binary mixtures consisting of Aliquat 336 
and Cyanex 272 or their mixtures with other extractants has a significant effect on the extraction of hydrogen ions in inorganic acids [11,12]. It has also been reported that some mixtures fail to enhance the extraction of hydrogen ions $[6,13]$. Therefore, the hydrogen ion extraction behavior of binary mixed systems deserves investigation.

Ionic liquids, known as green chemicals, have been extensively employed in many fields and in many processes, including catalysis, electrochemistry, organic synthesis, and the separation and recovery of metals [14-16]. One of the common ionic liquids can be prepared in the laboratory by mixing Aliquat 336 and organophosphorus acids like Cyanex 272. Many studies have demonstrated the excellent efficiency of ionic liquids derived from Aliquat 336 and Cyanex 272 in solvent extraction systems [17-19]. However, very little research has investigated the use of ionic liquids to extract hydrogen ions. It has been observed that during the extraction of metal ions by ionic liquids, the equilibrium $\mathrm{pH}$ of the aqueous phase can be higher than the initial $\mathrm{pH}$ in the range from 3 to $6[17,18,20]$. Since metal ions can be precipitated when the solution $\mathrm{pH}$ is higher than a certain threshold, control of solution $\mathrm{pH}$ is very important in the continuous operation of solvent extraction.

In synergistic solvent extraction, the distribution ratios of the mixtures are higher than the sum of the distribution ratios of the individual components in the mixtures [21]. To the best of our knowledge, the mechanism of hydrogen ion extraction by ionic liquids has not yet been identified. Therefore, in this study, ionic liquids consisting of a mixture of Aliquat 336 and Cyanex 272 were employed to investigate the extraction of hydrogen ions. The mechanism of hydrogen ion extraction by ionic liquids was identified using the slope analysis method, and varying some parameters including solution $\mathrm{pH}$, the concentration of the ionic liquid and chloride ions. The motivation of this work was to identify the change in solution $\mathrm{pH}$ during extraction by ionic liquid. Our results can explain the change in solution $\mathrm{pH}$ during the extraction of metal ions from a weak acidic solution by an ionic liquid prepared from Aliquat 336 and Cyanex 272. This result also shows that the ionic liquid $\mathrm{R}_{4} \mathrm{NA}$ has the potential to extract acids from aqueous solutions, and thus this work can be applied to recover inorganic acids by extraction with $\mathrm{R}_{4} \mathrm{NA}$.

\section{EXPERIMENTAL}

The acidity of the solution was adjusted by adding doubly distilled water to concentrated $\mathrm{HCl}$ (Daejung Co., 35\%). $\mathrm{NaCl}$ (Tedia Company, Inc., 99\%) was employed to fix the ionic strength of the solution at a constant value. The extractants Alamine 336 (BASF Co., 95\%), Aliquat 336 (NMethyl-N, N, N-trioctylammonium chloride, BASF Co., 93\%), Cyanex 272 (bis(2,4,4-trimethylpentyl)phosphinic acid, Cytec Inc., 85\%) were used without employing any purification. The structures and properties of these extractants are shown in Table 1. An ionic liquid $\left(\mathrm{R}_{4} \mathrm{NA}\right)$ was prepared by mixing an equimolar concentration of Aliquat 336 $\left(\mathrm{R}_{4} \mathrm{NCl}\right)$ and Cyanex 272 (HA) according to the method reported in the literature [11]. Kerosene (Samchun Pure Chemical Co.) was used as a diluent and all the other chemicals used were of analytical grade.

The extraction experiments were conducted by mixing equal volumes of aqueous and organic phases in a screwed cap bottle for 30 min using a Burrell wrist action shaker (model 75, USA) at ambient temperature. The aqueous phase was separated using a separation funnel after mixing the two phases for $30 \mathrm{~min}$. The initial and equilibrium $\mathrm{pH}$ values of the aqueous solution were measured three times using an Orion Star thermal scientific pH meter (model A221, USA). Additionally, the concentration of hydrogen ions in the aqueous phase was also measured before and after extraction by volumetric titration method [22]. When the solution $\mathrm{pH}$ was higher than 4 , it was difficult to determine the concentration of hydrogen ions by titration method, owing to the negligible concentration of hydrogen ions. Since the ionic strength of the solution was controlled to $0.1 \mathrm{M}$, the change in the concentration of hydrogen ions during the extraction was determined from the solution $\mathrm{pH}$ values when the solution $\mathrm{pH}$ was higher than 4 . The concentration of hydrogen ions in the organic phase was calculated by mass balance. The distribution ratio $(D)$ was calculated as the concentration of hydrogen ions in the organic phase to that in the aqueous phase at equilibrium. An ultraviolet visible (UV1800, Shimadzu, Japan) and Fourier transform infrared (FTIR-Vertex $80 \mathrm{~V}$, Bruker, Germany) spectrometers were employed to analyze the spectra of reagents before and after extraction. 
Table 1. Properties and chemical structures of the extractants.

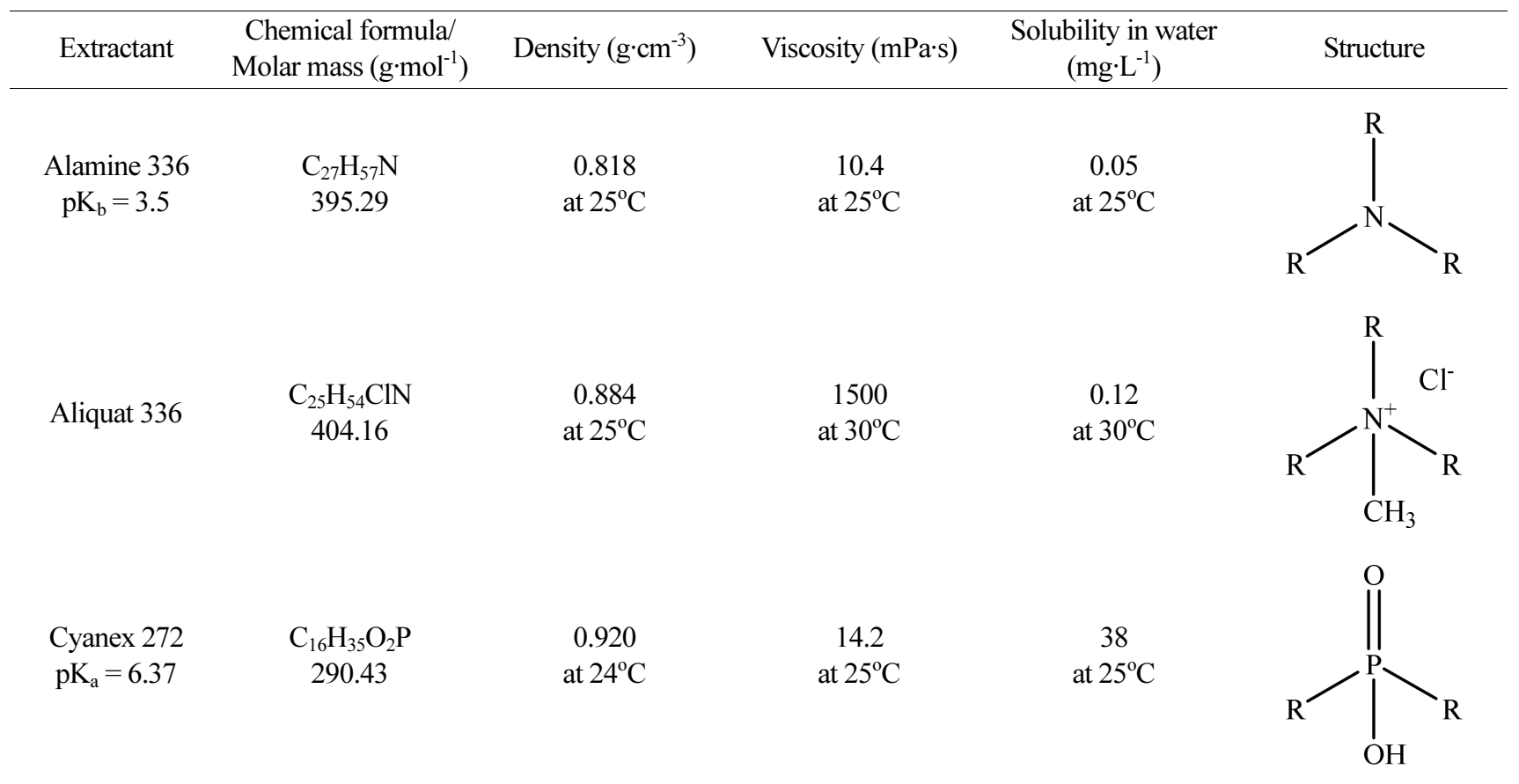

$\mathrm{R}$ denotes the alkyl groups.

\section{RESULTS AND DISCUSSION}

\subsection{Effect of $\mathrm{pH}$ on the extraction of hydrogen ions}

Five kinds of extractants (single Alamine 336 and Aliquat 336, the mixture of Alamine 336 and Aliquat 336 with Cyanex 272 and ionic liquid $\mathrm{R}_{4} \mathrm{NA}$ ) were employed to investigate their hydrogen ion extraction behavior from chloride solutions with an initial $\mathrm{pH}$ range of 0.05 to 5 . In these experiments, the concentration of each extractant was kept at $0.5 \mathrm{M}$ and the phase ratio of $\mathrm{O} / \mathrm{A}$ was fixed at unity. Among the 5 kinds of extractants, single Aliquat 336 and its mixture with Cyanex 272 did not extract any hydrogen ions in the experimental range (see Figure 1). The extraction percentage of hydrogen ions by Aliquat 336 and the mixture of Aliquat 336 and Cyanex 272 was nil due to their natural structural properties, that is, Aliquat 336 is an ammonium salt and Cyanex 272 is an acidic extractant.

The extraction percentage of hydrogen ions by Alamine 336 and $\mathrm{R}_{4} \mathrm{NA}$ were similar to each other. Both increased as the initial $\mathrm{pH}$ was increased from 0.05 to 0.5 , and then remained almost constant with further increase up to 5 . A

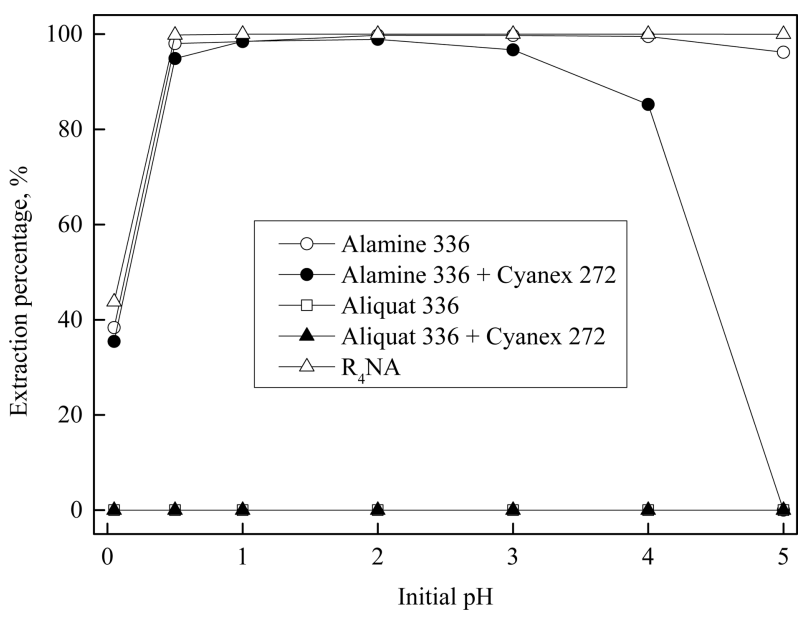

Fig. 1. Effect of solution $\mathrm{pH}$ on the extraction of hydrogen ion by the extractants.

small decrease in the extraction percentage of hydrogen ions by Alamine 336 was observed when the initial $\mathrm{pH}$ was higher than 4 , which might be ascribed to the protonation reaction of Alamine 336 [12,23]. The extraction reaction of hydrogen ions by Alamine $336\left(\mathrm{R}_{3} \mathrm{~N}\right)$ and $\mathrm{R}_{4} \mathrm{NA}$ from chloride solution can be represented as Eqs. (1) and (2-3), respectively $[11,24]$. 
Table 2. The values of $\mathrm{pH}$ before and after the extraction of hydrogen ion by the extractants.

\begin{tabular}{cccccccc}
\hline Initial $\mathrm{pH}$ & 0.05 & 0.50 & 1.00 & 2.00 & 3.00 & 4.00 & 5.00 \\
\hline Equilibrium $\mathrm{pH}_{\mathrm{A} 336+\mathrm{C} 272}$ & 0.24 & 1.79 & 2.82 & 3.83 & 4.47 & 4.83 & 4.86 \\
Equilibrium $\mathrm{pH}_{\mathrm{A} 336}$ & 0.26 & 2.30 & 2.80 & 4.48 & 5.57 & 6.31 & 6.42 \\
Equilibrium $\mathrm{pH}_{\mathrm{R} 4 \mathrm{NA}}$ & 0.31 & 3.19 & 6.52 & 8.34 & 8.43 & 8.63 & 8.71 \\
\hline
\end{tabular}

$[$ Extractant $]=0.5 \mathrm{M} ;[\mathrm{NaCl}]=0.1 \mathrm{M} ;$ A336 denotes Alamine 336; C272 denotes Cyanex 272.

$$
\begin{aligned}
& \mathrm{R}_{3} \mathrm{~N}_{\text {org }}+\mathrm{H}_{\text {aq }}^{+}+\mathrm{Cl}_{\text {aq }}^{-}=\mathrm{R}_{3} \mathrm{~N} \cdot \mathrm{HCl}_{\text {org }} \\
& \mathrm{R}_{4} \mathrm{NA}_{\text {org }}+\mathrm{H}_{\text {aq }}^{+}+\mathrm{Cl}_{\text {aq }}^{-}=\mathrm{R}_{4} \mathrm{NCl} \cdot \mathrm{HA}_{\text {org }} \\
& \mathrm{R}_{4} \mathrm{NA}_{\text {org }}+\mathrm{H}_{\text {aq }}^{+}+\mathrm{Cl}_{\text {aq }}^{-}=\mathrm{R}_{4} \mathrm{NA} \cdot \mathrm{HCl}_{\text {org }}
\end{aligned}
$$

In the mixture of Alamine 336 and Cyanex 272, hydrogen ion extraction efficiency increased as the initial $\mathrm{pH}$ increased up to 2, and then decreased with a further increase in initial $\mathrm{pH}$ of the solution. At an initial $\mathrm{pH}$ of 5 , hydrogen ions cannot be extracted by the binary mixture because some competitive reactions occur during the extraction. Before the extraction of hydrogen ions, an amine salt $\left(\mathrm{R}_{3} \mathrm{NHA}\right)$ may form through the ion-pair formation reaction when Alamine 336 is mixed with Cyanex 272, as represented by Eq. (4). Then, hydrogen ions can be extracted by the displacement reaction of the amine salt, as represented in Eq. (5). The other displacement reaction can occur between the anionic species in the organic mixture and chloride ions (Eq. (6)) [12,23]. Eq. (7) indicates that the interaction reaction between Cyanex 272 and the protonated amine results in the release of free acid from the organic phase and thus reduces the extraction of hydrogen ions. Therefore, the extraction percentage of hydrogen ions by the mixture of Alamine 336 and Cyanex 272 was negligible when the initial $\mathrm{pH}$ was 5 .

$$
\begin{aligned}
& \mathrm{R}_{3} \mathrm{~N}_{\text {org }}+\mathrm{HA}_{\text {org }}=\mathrm{R}_{3} \mathrm{~N} \cdot \mathrm{HA}_{\text {org }} \\
& \mathrm{R}_{3} \mathrm{~N} \cdot \mathrm{HA}_{\text {org }}+\mathrm{H}^{+}{ }_{\text {aq }}+\mathrm{Cl}_{\text {aq }}^{-}=\mathrm{R}_{3} \mathrm{~N} \cdot \mathrm{HCl}_{\text {org }}+\mathrm{HA}_{\text {org }} \\
& \mathrm{R}_{3} \mathrm{~N} \cdot \mathrm{HA}_{\text {org }}+\mathrm{Cl}_{\text {aq }}^{-}=\mathrm{R}_{3} \mathrm{~N} \cdot \mathrm{HCl}_{\text {org }}+\mathrm{A}_{\text {aq }}^{-} \\
& \mathrm{R}_{3} \mathrm{~N} \cdot \mathrm{HCl}_{\text {org }}+\mathrm{HA}_{\text {org }}=\mathrm{R}_{3} \mathrm{~N} \cdot \mathrm{HA}_{\text {org }}+\mathrm{HCl}_{\text {aq }}
\end{aligned}
$$

The results indicate that ion-pair formation, the protonation of amine, anion exchange, and displacement reactions can occur when an amine interacts with an organophosphorus acid [23]. Moreover, the extraction behavior of hydrogen ions by the above-mentioned extractants depends on the solution $\mathrm{pH}$. Table 2 shows the equilibrium $\mathrm{pH}$ values of the solution<smiles></smiles><smiles>O[14C]1=[14C](O)[Te](O)[In]1O</smiles>

Fig. 2. The interaction of $\mathrm{Na}^{+}$and $\mathrm{Cl}^{-}$ions by water in solution [25].

with these extractants. The equilibrium $\mathrm{pH}$ increased as the initial $\mathrm{pH}$ increased. This implies that hydrogen ions were well extracted into the organic phase by employing Alamine 336, the mixture of Alamine 336 and Cyanex 272, and $\mathrm{R}_{4} \mathrm{NA}$. Comparing these three types of extractants, the extraction efficiency and the variation in the equilibrium $\mathrm{pH}$ by $\mathrm{R}_{4} \mathrm{NA}$ was higher than that of Alamine 336 and its mixture with Cyanex 272. Therefore, the R ${ }_{4} \mathrm{NA}$ extractant was chosen for further experiments.

The formation of an emulsion and difficulty in phase separation were observed when the solution $\mathrm{pH}$ was higher than 0.5 while employing $0.5 \mathrm{M}$ of each extractant. To circumvent these phenomena, sodium chloride was added to the solution. In addition, the solubility of some extractants in water implies that there is an interaction between the extractants and water molecules that may interfere the extraction of hydrogen ions (see Table 1). Figure 2 shows that the solvation of cations $\left(\mathrm{Na}^{+}\right)$and anions $\left(\mathrm{Cl}^{-}\right)$by water molecules leads to aqueous stability. That is, the cations and anions can interact with water molecules by electrostatic interactions or the formation of hydrogen bonding, which improves phase separation [25].

\subsection{Mechanism of hydrogen ion extraction}

Since few studies have been conducted to analyze the hydrogen ion extraction behavior of the ionic liquid $\mathrm{R}_{4} \mathrm{NA}$, 


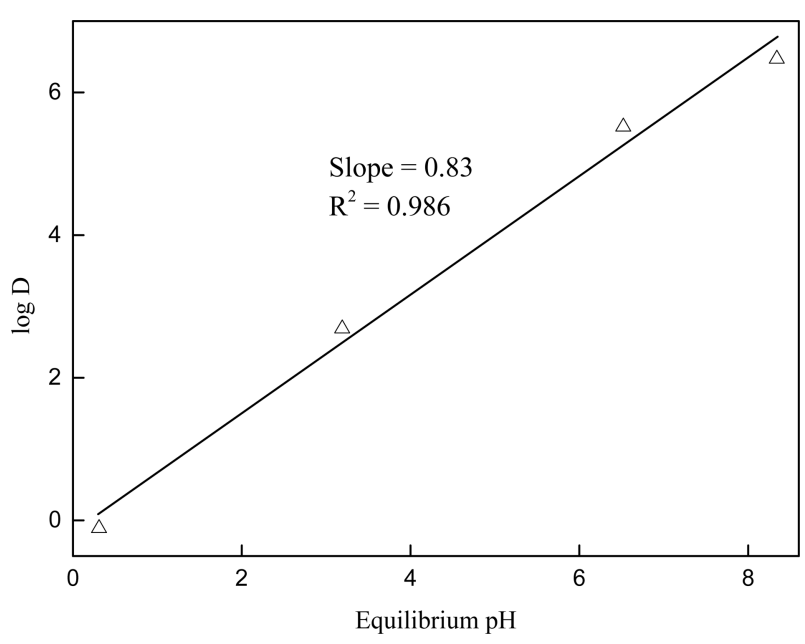

Fig. 3. Plot of $\log \mathrm{D}$ vs equilibrium $\mathrm{pH}$. Experimental condition: $[\mathrm{NaCl}]=0.1 \mathrm{M}, \mathrm{O}: \mathrm{A}=1: 1,\left[\mathrm{R}_{4} \mathrm{NA}\right]=1 \mathrm{M}$.

the extraction reaction of hydrogen ions by $\mathrm{R}_{4} \mathrm{NA}$ was investigated here by employing the slope analysis method. In order to examine the effect of solution $\mathrm{pH}$ on the extraction of hydrogen ions, $0.1 \mathrm{M} \mathrm{NaCl}$ was added to the solution and the initial $\mathrm{pH}$ was varied from 0.05 to 2 . The concentration of $\mathrm{R}_{4} \mathrm{NA}$ was fixed at $1 \mathrm{M}$. In all the experiments, solvent extraction was carried out at an $\mathrm{O} / \mathrm{A}$ phase ratio of unity. The plot of $\log \mathrm{D}$ versus equilibrium $\mathrm{pH}$ for hydrogen ion extraction is shown in Figure 3. The slope value of the straight line was 0.83 , indicating that one mole of hydrogen ions takes part in the extraction. The results agree well with Eqs (2) and (3).

In order to investigate the effect of extractant concentration on the extraction of hydrogen ions from chloride solution, the concentration of $\mathrm{R}_{4} \mathrm{NA}$ was varied from 0.1 to $0.5 \mathrm{M}$. In these experiments, the initial $\mathrm{pH}$ of the solution was fixed at 2 and sodium chloride concentration was controlled at $0.1 \mathrm{M}$. Figure 4 shows the plot of $\log \mathrm{D}$ versus $\log \left[\mathrm{R}_{4} \mathrm{NA}\right]$ for the extraction data. The value of the slope was 1.96, indicating that two moles of $\mathrm{R}_{4} \mathrm{NA}$ were associated with one mole of hydrogen ions in the reaction.

Generally, the molar ratio of hydrogen to chloride ions might be equal for reactions occurring in the aqueous solution. Since one mole of hydrogen ions is extracted by two moles of $\mathrm{R}_{4} \mathrm{NA}$, it can be predicted that one mole of chloride ions will be associated with one mole of hydrogen ions during the extraction. In order to verify this, the effect of

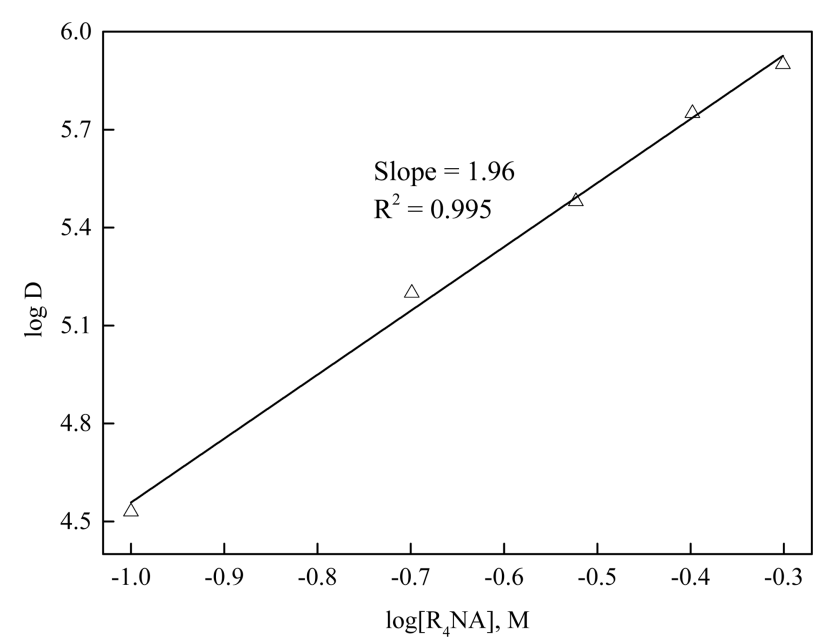

Fig. 4. Plot of $\log \mathrm{D}$ vs $\log \left[\mathrm{R}_{4} \mathrm{NA}\right]$. Experimental condition: $\mathrm{pH}_{\text {initial }}$ $=2.0,[\mathrm{NaCl}]=0.1 \mathrm{M}, \mathrm{O}: \mathrm{A}=1: 1$.

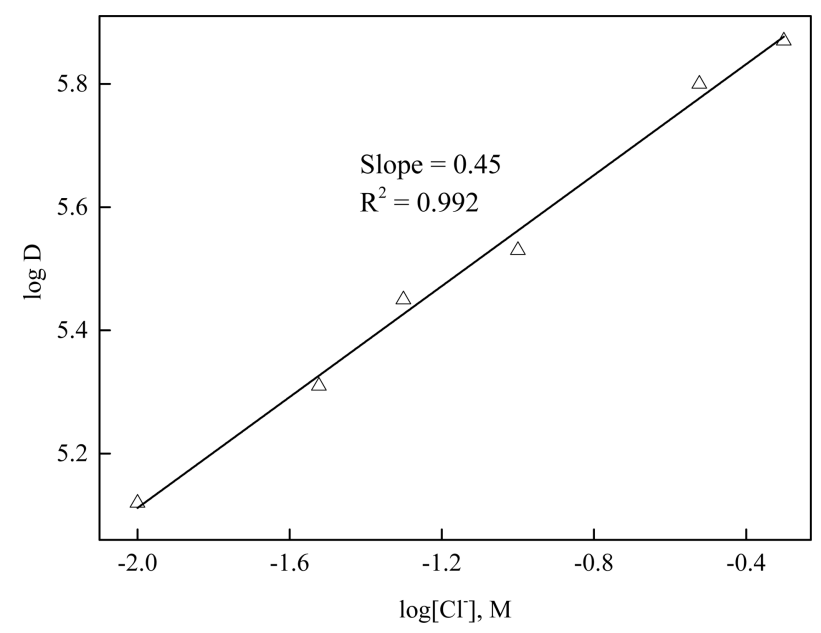

Fig. 5. Plot of $\log \mathrm{D}$ vs $\log \left[\mathrm{Cl}^{-}\right]$. Experimental condition: $\mathrm{pH}_{\text {initial }}=$ $2.0, \mathrm{O}: \mathrm{A}=1: 1,\left[\mathrm{R}_{4} \mathrm{NA}\right]=0.1 \mathrm{M}$.

chloride ion concentration on the extraction of hydrogen ions with $\mathrm{R}_{4} \mathrm{NA}$ was investigated, by controlling the concentration of sodium chloride from 0.01 to $0.5 \mathrm{M}$.

In these experiments, the concentration of $\mathrm{R}_{4} \mathrm{NA}$ was kept at $0.1 \mathrm{M}$ and the initial $\mathrm{pH}$ of the aqueous solution was adjusted to 2. The plot of $\log \mathrm{D}$ versus $\log \left[\mathrm{Cl}^{-}\right]$in Figure 5 gives a straight line with a slope value lower than one, implying that the chloride ions take part in the reaction. Since one mole of hydrogen ions was extracted into the organic phase, it should be accompanied by one mole of chloride ions. Among the added chloride salts, some of the sodium chloride can interact with water molecules (see Fig. 2), while 
the rest participates during the extraction by $\mathrm{R}_{4} \mathrm{NA}$.

Considering the dependence of $\log \mathrm{D}$ on the equilibrium $\mathrm{pH}$, the concentration of sodium chloride and $\mathrm{R}_{4} \mathrm{NA}$, the overall extraction reaction of hydrogen ions in chloride solution with ionic liquid $\left(\mathrm{R}_{4} \mathrm{NA}\right)$ can be described by Eq. (8). Eq. (8) shows that the extraction of hydrogen and chloride ions with $\mathrm{R}_{4} \mathrm{NA}$ is similar to that of neutral extractants. Therefore, some further experiments should be performed to verify the species extracted by $\mathrm{R}_{4} \mathrm{NA}$ ionic liquid.

$$
2 \mathrm{R}_{4} \mathrm{NA}_{\text {org }}+\mathrm{H}_{\text {aq }}^{+}+\mathrm{Cl}_{\text {aq }}^{-}=\left(\mathrm{R}_{4} \mathrm{NA}\right)_{2} \cdot \mathrm{HCl}_{\text {org }}
$$

\subsection{Analysis of the species extracted by} ionic liquids $\left(\mathrm{R}_{4} \mathrm{NA}\right)$

To investigate the species extracted by $\mathrm{R}_{4} \mathrm{NA}$ after the extraction of hydrogen ions in chloride solution, UV-Vis absorption and FT-IR spectra of the extractant were recorded. The samples were prepared by fixing the concentration of sodium chloride at $0.1 \mathrm{M}$ and adjusting the initial $\mathrm{pH}$ of chloride solution at 2 . The aqueous phase was contacted with the organic phase at an O/A phase ratio of unity. The concentration of $\mathrm{R}_{4} \mathrm{NA}$ was $1 \mathrm{M}$ and a mixture of $0.5 \mathrm{M}$ Aliquat 336 and $0.5 \mathrm{M}$ Cyanex 272 in kerosene was also prepared for comparison with $\mathrm{R}_{4} \mathrm{NA}$ before extraction. The obtained results are shown in Figure 6. $\mathrm{R}_{4} \mathrm{NA}$ before extraction showed lower intensity than the mixture of Aliquat 336 and Cyanex 272, indicating that the ionic liquid was successfully prepared. Based on the results, ionic liquid $\mathrm{R}_{4} \mathrm{NA}$ after extraction had the strongest intensity, and the intensity was nearly two times as strong as the intensity of $\mathrm{R}_{4} \mathrm{NA}$ before extraction. It can be said that hydrogen and chloride ions were transferred from the aqueous to the organic phase.

Figure 7 presents the FT-IR spectra of the extractants before and after the extraction of hydrogen ions. Most of the significant changes occurred in the range of $650-1700 \mathrm{~cm}^{-1}$. The spectra in Fig. 7 showed the frequencies at 723, 955, $1172,1236,1365-1378$, and $1465 \mathrm{~cm}^{-1}$, corresponding to the stretching of P-C, P-O-H, P=O, C-N, C-H, and $\left(\mathrm{CH}_{3}\right) \mathrm{N}^{+}$ groups, respectively, which is considered to be an important vibrational characteristic of Cyanex 272 and Aliquat 336.

There were some changes in the vibration frequency between $\mathrm{R}_{4} \mathrm{NA}$ and a mixture of Aliquat 336 and 272

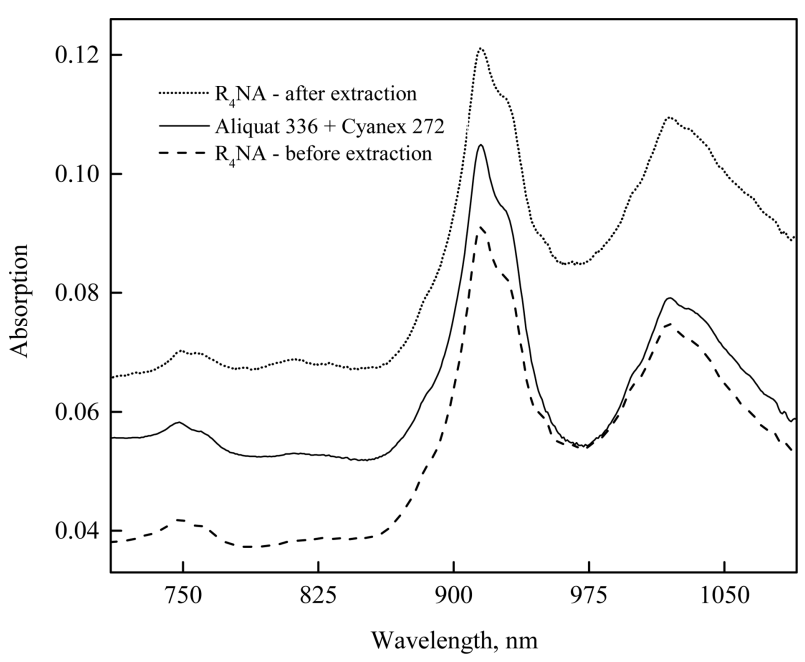

Fig. 6. UV-visible spectra of reagents before and after extraction of hydrogen ion. Experimental condition: $\mathrm{pH}_{\text {initial }}=2.0,[\mathrm{NaCl}]=0.1$ $\mathrm{M},\left[\mathrm{R}_{4} \mathrm{NA}\right]=1 \mathrm{M},[$ Aliquat 336$]=[$ Cyanex 272] $=0.5 \mathrm{M}, \mathrm{O}: \mathrm{A}=$ $1: 1$.

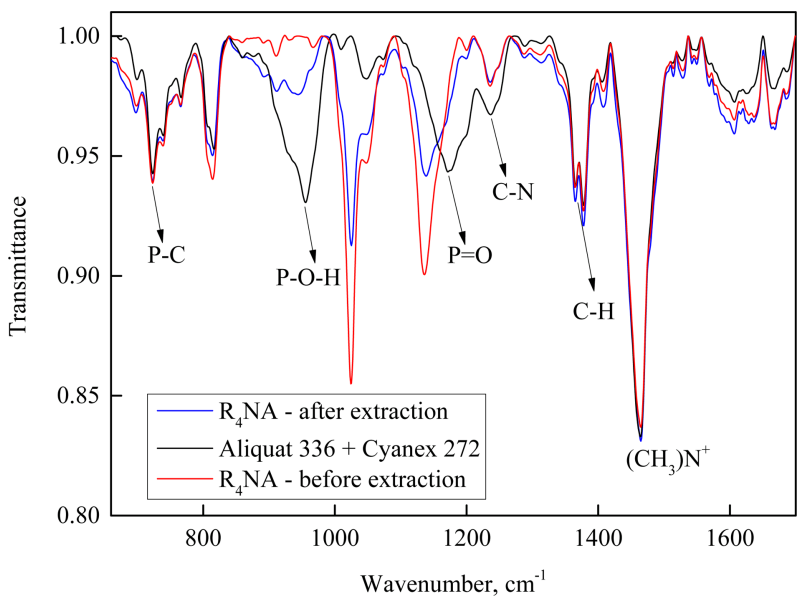

Fig. 7. FT-IR spectra of reagents before and after extraction of hydrogen ion. Experimental condition: $\mathrm{pH}_{\text {initial }}=2.0,[\mathrm{NaCl}]=0.1$ $\mathrm{M},\left[\mathrm{R}_{4} \mathrm{NA}\right]=1 \mathrm{M},[$ Aliquat 336$]=[$ Cyanex 272] $=0.5 \mathrm{M}, \mathrm{O}: \mathrm{A}=$ $1: 1$

Cyanex. Namely, the medium frequencies at $955 \mathrm{~cm}^{-1}$ of P$\mathrm{O}-\mathrm{H}$ group and $1172 \mathrm{~cm}^{-1}$ of $\mathrm{P}=\mathrm{O}$ group in the mixture shifted to low-intensity bands at $911 \mathrm{~cm}^{-1}$ and a strong frequency at $1136 \mathrm{~cm}^{-1}$ in $\mathrm{R}_{4} \mathrm{NA}$, respectively. This showed that the prepared ionic liquid $\mathrm{R}_{4} \mathrm{NA}$ had different characteristics than the original precursors. Comparing the FT-IR spectra of $\mathrm{R}_{4} \mathrm{NA}$ before and after hydrogen ion extraction, no new peaks appeared in the experimental ranges. These results indicate that the ingredient $\mathrm{R}_{4} \mathrm{NA}$ participated in the extraction of hydrogen ions. Especially at 
Table 3. Change in the values of $\mathrm{pH}$ before and after extraction by the extractants.

\begin{tabular}{ccccc}
\hline Extractants & Aliquat 336 + Cyanex 272 & Alamine 336+ Cyanex 272* & Alamine 336 + Cyanex 272 & $\mathrm{R}_{4} \mathrm{NA}$ \\
\hline Initial $\mathrm{pH}$ & 1.0 & 1.0 & 1.0 & 1.0 \\
Equilibrium $\mathrm{pH}$ & 0.98 & 2.14 & 2.82 & 6.52 \\
Extraction percentage, $\%$ & 0.00 & 92.8 & 98.5 & 99.9 \\
\hline
\end{tabular}

Superscript * represents the data reported from the reference [12]

frequencies of 1025 and $1136 \mathrm{~cm}^{-1}$, the intensity of $\mathrm{R}_{4} \mathrm{NA}$ after extraction was reduced to almost half compared to that before extraction, indicating the strong interaction between hydrogen ions and $\mathrm{R}_{4} \mathrm{NA}$.

These obtained results suggest that the hydrogen ions extraction reaction by $\mathrm{R}_{4} \mathrm{NA}$ in chloride solution followed Eq. (8). It might be said that a solvation reaction was responsible for the extraction. The equilibrium constant $\left(K_{e}\right)$ of Eq. (8) can be given as Eq. (9). Taking the logarithm of Eq. (9) and rearranging, leads to Eq. (11), indicating the dependence of the distribution ratio on the equilibrium constant, the concentration of the ionic liquid and chloride ions.

$$
\begin{aligned}
& K_{e}=\left(\left[\left(\mathrm{R}_{4} \mathrm{NA}\right)_{2} \cdot \mathrm{HCl}\right]_{\text {org }}\right) /\left(\left[\mathrm{R}_{4} \mathrm{NA}\right]_{\text {org }}^{2} \cdot\left[\mathrm{H}^{+}\right]_{\mathrm{aq}} \cdot[\mathrm{Cl}]_{\text {aq }}^{-}\right) \\
& \text {or } K_{e}=D /\left(\left[\mathrm{R}_{4} \mathrm{NA}\right]_{\text {org }}^{2} \cdot[\mathrm{Cl}]_{\text {aq }}^{-}\right) \\
& \text {where } D=\left(\left[\left(\mathrm{R}_{4} \mathrm{NA}\right)_{2} \cdot \mathrm{HCl}\right]_{\text {org }}\right) /\left(\left[\mathrm{H}^{+}\right]_{\mathrm{aq}}\right) \\
& \log D=\log K_{e}+2 \log \left[\mathrm{R}_{4} \mathrm{NA}\right]+\log \left[\mathrm{Cl}^{-}\right]
\end{aligned}
$$

\subsection{Comparison of the extraction of} hydrogen ions by mixture extractants

As seen in Fig. 1, the combination of Alamine 336 and Cyanex 272 exhibited a synergistic effect on the extraction of hydrogen ions in the initial $\mathrm{pH}$ range from 0.5 to 3 , which agrees well with the previous work [12]. Meanwhile, the nature of the interaction between Aliquat 336 and Cyanex 272 does not affect the synergism in the extraction reaction. Since the ionic liquid $\mathrm{R}_{4} \mathrm{NA}$ was prepared by mixing Aliquat 336 and Cyanex 272, the hydrogen ions extraction behavior of $\mathrm{R}_{4} \mathrm{NA}$ is of great significance. A comparison of the extraction of hydrogen ions by several binary mixtures is given in Table 3. Based on Table 3, there were some differences between this work and previous work in the results for equilibrium $\mathrm{pH}$ and the percentages of hydrogen ion extraction by the mixture of Alamine 336 and Cyanex 272 [12]. For instance, the extraction percentage of hydrogen ions by the mixture of Alamine 336 and Cyanex 272 in this system $(98.5 \%)$ was higher than that in the previous work $(92.8 \%)$. This may be attributed to the presence of sodium chloride in the solution, which affects the extraction.

Moreover, the ionic liquid $\mathrm{R}_{4} \mathrm{NA}$ prepared from Cyanex 272 and Aliquat 336 showed better efficiency at extracting hydrogen ions. The change in equilibrium $\mathrm{pH}$ value after hydrogen ion extraction by $\mathrm{R}_{4} \mathrm{NA}$ was three times higher than by the mixture of Alamine 336 and Cyanex 272 in the previous work. $\mathrm{R}_{4} \mathrm{NA}$ exhibited superior extraction characteristics compared to the other mixture extractants in terms of a change in solution $\mathrm{pH}$.

It can be said that the selective extraction of hydrogen ions by this kind of ionic liquid greatly affects the control of solution $\mathrm{pH}$ during the extraction of metals from weak acidic solution. The formation of precipitates can result in crud formation which militates against a continuous solvent extraction operation. Therefore, the selection of an appropriate concentration of ionic liquid is very important, to control solution $\mathrm{pH}$ within the stable region of the target metal ions. In order to accomplish this, it is necessary to develop a thermodynamic model of the solvent extraction of metals from weak acidic solution by an ionic liquid.

\section{CONCLUSIONS}

The solvent extraction of hydrogen ions from chloride solution was investigated using Alamine 336, Aliquat 336 and its mixture with Cyanex 272, and ionic liquids $\left(\mathrm{R}_{4} \mathrm{NA}\right)$. The extractants' hydrogen ion extraction behavior was found to depend strongly on the solution $\mathrm{pH}$. When the initial $\mathrm{pH}$ was increased, the equilibrium $\mathrm{pH}$ increased when using Alamine 336, the mixture of Alamine 336 and Cyanex 272, and $\mathrm{R}_{4} \mathrm{NA}$. Among these three extractants, $\mathrm{R}_{4} \mathrm{NA}$ showed the best performance for the extraction of hydrogen ions when the initial $\mathrm{pH}$ range was from 0.05 to 5 . The formation of an 
emulsion and difficulty in phase separation were observed, and suppressed by adding sodium chloride. UV-Vis and FTIR spectra analyses verified the extracted species after hydrogen ion extraction by $\mathrm{R}_{4} \mathrm{NA}$. The solvent extraction reaction of hydrogen ions by $\mathrm{R}_{4} \mathrm{NA}$ was determined by applying a slope analysis method to the extraction data. Further work is necessary to develop a thermodynamic model which considers the change in solution $\mathrm{pH}$ during the extraction of metal ions in weak acidic solution by an ionic liquid.

\section{ACKNOWLEDGEMENTS}

This study was supported by a grant from the Korean Research Foundation (2018R1D1A1BO7044951). We express sincere thanks to the Korea Basic Science Institute (KBSI), Gwangju branch for providing FT-IR data.

\section{REFERENCES}

1. Z. Mohammadpour and H. R. Zare, Met. Mater. Int. 24, 761 (2018).

2. M. T. Nguyen, J. H. Kim, J. G. Lee, and J. C. Kim, Met. Mater. Int. 24, 821 (2018).

3. D. F. Haghshenas, D. Darvishi, H. Rafieipour, E. K. Alamdari and A. A. Salardini, Hydrometallurgy 97, 173 (2009).

4. W. Rudolfs, Ind. Eng. Chem. 35, 227 (1943).

5. C. H. Shin, J. Y. Kim, J. Y. Kim, H. S. Kim, H. S. Lee, D. Mohapatra, J. W. Ahn, J. G. Ahn, and W. Bae, J. Hazard. Mater. 163, 729 (2009).

6. R. Banda, T. H. Nguyen, and M. S. Lee, Chem. Process Eng.- Inz. 34, 153 (2013).

7. J. Stas and H. Alsawaf, Period. Polytech. Chem. Eng. 60, 130 (2016).

8. A. S. Vieux and N. Rutagengwa, J. Phys. Chem. 80, 1283
(1976).

9. F. J. Alguacil and F. A. López, Hydrometallurgy 42, 245 (1996).

10. A. Apelblat, J. Chem. Soc. Dalt. Trans. 0, 1198 (1973).

11. A. Fortuny, M. T. Coll, and A. M. Sastre, Sep. Purif. Technol. 97, 137 (2012).

12. Y. Liu, H. S. Jeon, and M. S. Lee, Hydrometallurgy 155, 44 (2015).

13. M. N. Le, T. H. Nguyen, and M. S. Lee, Geosystem Eng. In press (2018).

14. N. V. Plechkova and K. R. Seddon, Chem. Soc. Rev. 37, 123 (2008).

15. X. Sun, Y. Ji, Y. Liu, J. Chen, and D. Li, AIChE J. 56, 989 (2009).

16. C. Park, B. Yoo, and J. Lee, Korean J. Met. Mater. 56, 645 (2018).

17. N. Devi and L. B. Sukla, Miner. Process. Extr. Metall. Rev. 7508, 1 (2018).

18. J. Castillo, M. T. Coll, A. Fortuny, P. Navarro Donoso, R. Sepúlveda, and A. M. Sastre, Hydrometallurgy 141, 89 (2014).

19. C. G. Oh and M. S. Lee, Korean J. Met. Mater. 56, 870 (2018).

20. A. Rout, K. A. Venkatesan, T. G. Srinivasan, and P. R. Vasudeva Rao, Sep. Purif. Technol. 95, 26 (2012).

21. X. Sun, Y. Ji, L. Zhang, J. Chen, and D. Li, J. Hazard. Mater. 182, 447 (2010).

22. A. I. Vogel, Textbook of Quantitative Chemical Analysis, $5^{\text {th }}$ ed., pp. 295-296, Longman Scientific \& Technical, New York (1989).

23. A. M. Eyal and R. Canari, Ind. Eng. Chem. Res. 34, 1789 (1995).

24. K. Sarangi, E. Padhan, P. V. R. B. Sarma, K. H. Park, and R. P. Das, Hydrometallurgy 84, 125 (2006).

25. T. Okuyama and H. Maskill, Organic Chemistry: a mechanistic approach, $1^{\text {st }}$ ed., pp. 67-68, Oxford University Press, Oxford, UK (2013). 